\title{
História e economia em Hume e Kant
}

\author{
History and economy in Hume and Kant
}

NORBERT WASZEK ${ }^{a}$

Tradução de Eveline CAMpos Hauck e LutTI Mıra

Numa passagem famosa de sua Riqueza das Nações, Adam Smith faz um elogio notável, e de certa forma surpreendente, a seu amigo David Hume:

\begin{abstract}
O comércio e as manufaturas gradualmente introduziram a ordem e o bom governo e, com eles, a liberdade e a segurança dos indivíduos [...]. Este, embora o último dos efeitos observados, é de longe o mais importante. Pelo que sei, o Sr. Hume foi o único autor até hoje a levá-lo em conta ${ }^{2}$.
\end{abstract}

O que torna essa manifestação particularmente surpreendente é a ênfase de Smith na originalidade de David Hume. "Até hoje”, diz Smith, ou até o momento, em outras palavras, até a data da publicação de seu livro em 1776, Hume teria sido o

\footnotetext{
${ }^{1}$ Esse artigo foi publicado em: Politik und Politeia. Formen und Probleme politischer Ordnung. Festgabe für Jürgen Gebhardt zum 65. Geburtstag. Ed. por Wolfgang Leidhold. Würzburg, Königshausen \& Neumann, 2000, p. 609-618. O autor gentilmente autorizou a tradução e publicação do artigo em língua portuguesa, traduzido por Eveline Campos Hauck e Lutti Mira, Bolsista Fapesp, Processo n²019/01286-1.

${ }^{2}$ Essa passagem é tirada do capítulo "Como o comércio das cidades contribuiu para o desenvolvimento do campo"; The Glasgow Edition of the Works and Correspondance of Adam Smith, vol. II, 1, ed. por R. H. Campbell and A. S. Skinner, Oxford, Clarendon, 1976, p. 412. [Para a tradução em português da citação de Smith, usamos SMITH, A. A Riqueza das Nações. Tradução de A. A. Rodrigues e E. Ostrensky, São Paulo: WMF Martins Fontes, 2019, vol. I, p. 512]
}

a Universidade Paris VIII, Saint-Denis, Paris. PhD, e-mail: norbert.waszek@gmail.com 
único autor a notar as felizes consequências políticas do progresso do comércio e das manufaturas. Esse comentário de Smith, por mais lisonjeiro que seja a David Hume, tomado sem precisões ou qualificações ulteriores, certamente deve ser criticado por inexatidão, pois outros autores discutiram a ligação entre comércio e liberdade antes de 1776. Mesmo sem deixar a Grã-Bretanha e, portanto, sem buscar pontos de vista comparáveis no pensamento francês, a fim de contradizer Adam Smith, pode-se evocar, entre seus contemporâneos e compatriotas escoceses, os trabalhos de Adam Ferguson, William Robertson e Sir James Steuart, os quais publicaram no final da década de 1760. Deve ser suficiente citar Steuart, cuja obra não é ainda tão amplamente conhecida como mereceria ser, em parte devido ao próprio silêncio de Adam Smith. Steuart escreve sobre a relação entre economia e política: "Quando um Estado começa a subsistir das consequências da indústria, há menos perigo de ser apoderado pelo poder do soberano"3.

Muitas explicações para o surpreendente elogio de Smith a Hume podem ser apresentadas. Embora Smith conhecesse a obra de Steuart, pode-se argumentar que ele se recusou a debater abertamente com o autor e simplesmente não quis mencioná-lo. Outra possibilidade é a de que Smith quis, sobretudo, insistir na prioridade da afirmação de Hume, mesmo que ele soubesse perfeitamente bem que Hume não fora o único escritor a tratar do assunto antes de 1776. O próprio Steuart, Smith poderia afirmar em defesa de seu ponto de vista, teria lido Hume e se inspirado em sua obra ${ }^{4}$. É igualmente possível usar o elogio de Smith a Hume, e essa foi a forma como os editores da edição bicentenária de Glasgow da Riqueza das Nações comentaram a observação do autor, para esclarecer quando e como essa parte da obra foi primeiro elaborada. Certamente se essa passagem fora escrita antes da publicação de Steuart (bem como da de Ferguson e Robertson), a ênfase de Smith na originalidade de Hume seria menos surpreendente.

\footnotetext{
${ }^{3}$ STEUART, J. An Inquiry into the Principles of Political Economy [1767], ed. por A. Skinner, Edinburgh and London, Oliver \& Boyd, 1966, vol. I. p. 217.

${ }^{4}$ A recente pesquisa de Andrew Skinner, incidentalmente, parece confirmar essa linha de argumentação, uma vez que documenta a origem humiana da obra de Steuart; veja SKINNER, A. S. The Shaping of Political Economy in the Enlightenment, In: SMITH, Adam. International Perspectives, ed. por H. Mizuta and Ch. Sugiyama, London: Macmillan, 1993. pp. 113-139.
} 
A intenção desse artigo é diferente: como hipótese, gostaria de considerar seriamente a originalidade de Hume, sobre a qual Smith insistiu. Na primeira parte, tentarei reconstruir o argumento de Hume de modo a apresentar sua originalidade 5 . $\mathrm{Na}$ segunda parte, examinarei o papel e o destino do argumento de Hume na filosofia da história de Kant, pois, como se sabe, a leitura que Kant fez de Hume foi uma das experiências mais cruciais em seu desenvolvimento intelectual ${ }^{6}$.

Hume discute a relação do comércio e da indústria com a liberdade — ou, mais precisamente, a relação entre os avanços em cada uma dessas duas esferas em sua História da Grã-Bretanha e em seu ensaio sobre o luxo, um ensaio que ele veio a chamar Do refinamento nas artes desde a edição de 1760 de seus Ensaios ${ }^{7}$. Em seu ensaio sobre o luxo, Hume formula sua tese como um princípio geral, ao passo que em sua História, a mesma tese surge frequentemente de considerações empíricas detalhadas $^{8}$. Nesse sentido, o ensaio sobre o refinamento foi apropriadamente chamado de "uma versão abreviada" da História". Kant conhecia ambos os textos de Hume, tal como é documentado em muitas passagens de suas obras e lições ${ }^{10}$.

\footnotetext{
${ }^{5}$ Para aqueles familiarizados com a história dos estudos sobre Hume, ficará óbvio que minhas perspectivas sobre Hume devem à interpretação de Duncan Forbes; veja a introdução à sua edição de HUME, D. The History of Great Britain: The reigns of James I and Charles I, ed. por Duncan Forbes, Harmondsworth, Penguin, 1970 [doravante citada como "Hume: History (Forbes)"]; FORBES, D. Hume's Philosophical Politics. Cambridge University Press, 1975; Hume and the Scottish Enlightenment, In: Philosophers of the Enlightenment, ed. por S. C. Brown. Brighton: Harvest Press, 1979, p. 94-109.

${ }^{6}$ Para uma pesquisa mais abrangente da relação de Kant com Hume, veja meu recente artigo: Histoire et Politique: Kant et ses prédécesseurs écossais. In: Kant, Philosophie de l'Histoire, ed. por N. Waszek [Revue Germanique Internationale, n 6] Paris: PUF, 1996, pp. 75-88.

${ }^{7}$ HUME, D. Essays, Moral and Political. Edinburgh, Alexander Kincaid, 1741. Usei a edição recente: Essays, Moral, Political and Literary. Ed. por E. F. Miller, Indianapolis: Liberty Classics, revised ed. 1987 - doravante citada como "HUME: Essays".

80 mesmo ponto pode ser expressado em termos de uma dupla vocação de Hume, como filósofo e como historiador; veja PHILLIPSON, N. Hume. London: Weidenfeld \& Nicolson, 1989, p. 15. Em seus Ensaios, escrevendo como filósofo, "Hume pretendeu descobrir o que era a civilização, e como ela poderia ser cultivada. Como historiador, pretendeu descobrir como ela se desenvolveu na Grã-Bretanha e como poderia ser preservada no futuro".

${ }^{9}$ HUME, History (Forbes), p. 39.

${ }^{10}$ Veja Kant's Gesammelte Schriften, ed. pela Königlich Preußischen Akademie der Wissenschaften zu Berlin, Berlin: Reimer [agora: De Gruyter], 1900 ss. [doravante citada como "AA" = Akademie Ausgabe], vol. XXVII, p. 80; vol. V, p. 320; vol. XV, pp. 200 e 592. Para mais informações sobre os textos em que Kant se mostra familiarizado com os escritos de Hume, veja: GAWLICK, G. und KREIMENDAHL, L., Hume in der deutschen Aufklärung, Umrisse einer Rezeptionsgeschichte. Stuttgart: Frommann-Holzboog, 1987, pp. 178 e 180.
} 
Em seu ensaio sobre o luxo, Hume se empenha em corrigir as duas posições extremas acerca do luxo correntes em seu tempo: por um lado, a perspectiva dos "homens de princípios libertinos", os quais "elogiam mesmo o luxo vicioso"; por outro, o ponto de vista defendido por "homens de moral severa", os quais "censuram o luxo mais inofensivo" ". Hume combate ambas as tendências e afirma "que as épocas de refinamento são as mais felizes e mais virtuosas". Para fundamentar sua posição, Hume pretende examinar "os efeitos do refinamento" na "vida privada" mas também — e esse aspecto é particularmente interessante — "na vida pública". Já na sua consideração sobre os efeitos do refinamento sobre a vida privada, Hume insiste na ligação entre um progresso nas artes mecânicas e seu equivalente nas artes liberais:

[...] umas não podem ser levadas à perfeição sem ser acompanhadas, em alguma medida, pelas outras. A mesma época que produz grandes filósofos e políticos, generais e poetas de renome, costuma ser abundantes em hábeis tecelões e construtores de navios. Não é razoável esperar que uma malha de lã seja tecida com perfeição numa nação que ignora a astronomia ou negligencia a ética. O espírito da época afeta todas as artes, e a mente humana, uma vez despertada de sua letargia e posta em ebulição, volta-se para todos os lados e faz aprimoramentos em cada arte e ciência ${ }^{12}$.

Quando Hume passa explicitamente para uma análise da benéfica influência do refinamento sobre a vida pública, ele começa declarando que as leis de um país

jamais podem ser levadas a algum grau de perfeição antes que a razão humana tenha refinado pelo exercício e pela aplicação nas artes mais comuns, ou, ao menos, nas artes do comércio e da manufatura ${ }^{13}$.

Hume então formula sua tese em termos mais gerais e a explica através de uma reflexão sobre a história: "que o progresso nas artes é antes propício à liberdade e tende naturalmente a preservar, se não a produzir, um governo livre" ${ }^{\prime 14}$. $\mathrm{Na}$ explicação histórica que oferece, Hume toma como ponto de partida aqueles países — ele os denomina "nações rudes e impolidas" - nos quais o cultivo do solo permanece a principal, ou mesmo a única, ocupação. Nesses países, diz Hume,

\footnotetext{
${ }^{11}$ HUME, Essays, p. 269. [Para a tradução em português, usamos HUME, D. A arte de escrever ensaio. Seleção Pedro Paulo Pimenta; tradução Márcio Suzuki e Pedro Paulo Pimenta. São Paulo: Iluminuras, 2008, p. 210 - doravante "HUME (2008)"]

${ }^{12}$ HUME, Essays, pp. 270ss. [HUME (2008), p. 211]

${ }^{13}$ HUME, Essays, p. 273. [HUME (2008), p. 213]

${ }^{14}$ HUME, Essays, p. 277. [HUME (2008), p. 217]
} 
a população é "dividida em duas classes: proprietários de terra e seus vassalos ou arrendatários". Os proprietários se tornam rapidamente "tiranetes" frente aos arrendatários e, em relação a seus pares, "eles têm de entrar em hostilidades e conflitos uns contra os outros" se desejarem manter sua independência, ou têm de "se submeter à tirania do seu soberano". Em tal situação, segundo Hume, a verdadeira liberdade sob leis iguais não pode existir para qualquer uma das duas classes. Por outro lado,

Onde [...] o luxo alimenta o comércio e a indústria, os camponeses se tornam ricos e independentes mediante o cultivo adequado da terra, enquanto os comerciantes e mercadores adquirem uma parcela da propriedade, o que confere respeito e autoridade aos homens dos estratos intermediários, a melhor e mais firme base da liberdade pública. [...] Eles anseiam por leis iguais, que assegurem sua propriedade e os pretejam da tirania, monárquica ou aristocrática ${ }^{15}$.

Hume mostra semelhante ponto de vista em sua História, mas com base em exemplos concretos que desenvolveu em muitas partes do livro ${ }^{16}$. Pode-se até mesmo dizer que é esse argumento que torna possível responder à questão muito disputada sobre se a História de Hume é uma história política ou mais propriamente uma história da civilização ${ }^{17}$ : para Hume, esses dois aspectos estão necessariamente conjugados. Porém, para retornar ao seu argumento e à forma como ele o explica em sua História, é essencial definir o conceito de liberdade que Hume pressupõe em toda a obra. Ao longo de seu livro, Hume empenha-se em distinguir a assim chamada "liberdade" ou "licenciosidade", para usar seu próprio termo encontrada por ele, por exemplo, na independência selvagem dos invasores alemães

\footnotetext{
${ }^{15}$ HUME, Essays, p. 277ss. [HUME (2008), p. 217, trad. modificada]

${ }^{16}$ Sobre a História de Hume, Duncan Forbes é, mais uma vez, o melhor guia, veja a introdução de sua edição da História de Hume [veja nota 4]. Sobre Hume enquanto historiador, veja também MOSSNER, E. C. An Apology for David Hume, Historian, In: Proceedings of the Modern Language Association, vol. 66 (1941), pp. 657-680; GIARRIZZO, G. David Hume, politico e storico. Torino: Einaudi, 1962; David Hume: Philosophical Historian, ed. por D. F. Norton and R. Popkin, New York, Bobbs-Merrill, 1965; Wexler, V. David Hume and the History of England. Philadelphia: American Philosophical Society, 1979; STREMMINGER, G. David Hume als Historiker, In: Zeitschrift für philosophische Forschung, vol. 40 (1986), pp. 161-180; PHILLIPSON, N. (1989) [veja nota 7]; Liberty in Hume's History of England, ed. por N. Capaldi and D. W. Livingston, Dordrecht/Boston/London: Kluwer, 1990.

${ }^{17}$ Veja MOSSNER, E. C. (1941); STEWART, J. B. The Moral and Political Philosophy of David Hume. New York: Columbia University Press, 1963; FORBES, D. (1970), p. 38ss.; PHILLIPSON, N. (1989), p. 139ss.
} 
do Império Romano - da verdadeira liberdade, garantida pelo estado de direito [rule of law] - encontrada por ele naquilo que chama de "monarquias civilizadas" da Europa moderna. A esse respeito, que vai contra o que numerosos leitores e críticos ingleses pensaram, ele identifica claramente a monarquia "constitucional" de acordo com o modelo inglês com a monarquia "absoluta" à la française: para Hume, ambas são "monarquias civilizadas" e "governos regulares"; em outras palavras, governos de lei, ao invés de despotismos arbitrários. Hume não se alinha àqueles que têm uma admiração unilateral pela "velha liberdade inglesa" ou pela antiga constituição inglesa. Para começo de conversa, para ele, não havia uma antiga constituição inglesa e, portanto, essa constituição não poderia ser reconquistada em 1688; havia apenas uma série de precedentes conflituosos. Ademais, Hume não é um inglês anglocêntrico, mas um escocês com perspectiva e leitura europeia, mas também estima e gosto particular pela França, onde ele, de acordo com sua nota autobiográfica, "uma vez pensou em se estabelecer" ${ }^{18}$. Cada uma das muitas passagens em que coloca a civilização política francesa no mesmo nível da inglesa é de fato uma crítica ao chauvinismo inglês. $\mathrm{O}$ próprio ensaio sobre o refinamento nas artes, sobre o qual o presente artigo tratou, fornece um bom exemplo dessa atitude:

Acredito que todo homem pensaria que sua vida ou fortuna estaria muito menos segura nas mãos de um moro ou de um tártaro que nas de um cavalheiro francês ou inglês, o estrato de homens mais civilizados nas mais civilizadas nações. ${ }^{19}$

O que é aparentemente uma comparação inocente pode ser lida como uma recusa a aceitar uma reivindicação exclusivamente inglesa da liberdade. Isso torna fácil entender por que Hume gozou de grande popularidade na França, onde se tornou conhecido por "le bon David", "le sage Hume" etc.

Para Hume não pode haver liberdade sem leis, e, em sua História, ele tenta mostrar as contradições que criaram, ou ao menos contribuíram, para criar esse estado de direito [rule of law]. As descrições que apresenta, em vários momentos de sua História, do estado da erudição e das letras, devem ser observadas neste contexto: a condição dos autores e de seu público, da instrução e dos estudos

\footnotetext{
${ }^{18}$ HUME, My own life, in: HUME, Essays, p. xxxix.

${ }^{19}$ HUME, Essays, p. 278. [HUME (2008), p. 218, trad. modificada]
} 
constitui, em toda época, um indicador ou medida do nível de "refinamento" de uma civilização. No mesmo capítulo, por exemplo, em que Hume apresenta o estado "da instrução e das artes” sob Jaime I, há uma explanação sobre finanças, comércio e manufaturas da época. Não parece exagero dizer que, quando Hume examina o desenvolvimento do comércio e da indústria em um dado período, ele o faz por causa de sua relação privilegiada com a história da liberdade. O progresso da sociedade é parte da história da liberdade. Quando Hume analisa a emergência e o avanço do que ele chama de "homens dos estratos intermediários", entre o campesinato e a aristocracia, ele é guiado pelo possível papel político que esse grupo de homens terão, pois "são a melhor e mais firme base para a liberdade pública".

Pode-se alegar que esse argumento não é humiano, mas parte de um idioma que seria por fim remontado a James Harrington. Porém, a tese de Hume - uma parte integral de "sua profunda crença nos poderes civilizatórios [...] do comércio", para usar a expressão de Nicholas Phillipson ${ }^{20}$ —, parece justo objetar, é muito mais específica do que uma posição geral de acordo com a qual "o poder resulta da propriedade" 21 .

II.

A segunda parte deste artigo empenha-se em encontrar o traço do argumento de Hume, tal como acima delineado, nos artigos de Kant a respeito da filosofia da história. Dois trechos de Kant servirão como pontos de partida na análise que segue: a primeira passagem provém do "Começo conjectural da história humana" (1786), a segunda é retirada da oitava proposição da "Ideia de uma história universal de um ponto de vista cosmopolita" $(1784)^{22}$. Nesses dois trechos, Kant considera a

\footnotetext{
${ }^{20}$ PHILLIPSON, N. (1989) [veja nota 7], p. 16.

${ }^{21}$ A seção sobre Hume na detalhada história do argumento harringtoniano de Raimund Ottow chega a uma conclusão similar; vide: OTTOW, R., Power follows property. Zu einem Topos der britischen politischen Herrschaftssoziologie im 17./18. Jahrhundert, In: Archives européennes de sociologie, 34 (1993), pp. 277-306; veja também MOORE, J., Hume's political science and the classical republican tradition, In: Canadian Journal of Political Science, 10 (1977), pp. 809-839, especialmente 816.

${ }^{22}$ RR = Kant, Schriften zur Geschichtsphilosophie, ed. por M. Riedel, Stuttgart, Reclam 1974; 21985, pp. 79 e ss., 33 e ss.; dentre as traduções em inglês, utilizei: OH = On history,
} 
relação entre o nível de desenvolvimento da indústria e do comércio a ser encontrado num país, e o nível de liberdade desfrutado no país em questão.

$\mathrm{Na}$ passagem do "Começo conjectural”, Kant considera “o agricultor que finalmente distancia-se tanto quanto possível daqueles que viviam a vida dos pastores"23. A fim de cultivar o solo, os agricultores devem assentar-se e construir moradia permanente. Para defender suas casas e sua propriedade, os agricultores "devem se organizar para dar assistência uns aos outros". Por essa razão, eles se juntam e constroem aldeias e cidades. Somente neste nível a divisão do trabalho e a troca de produtos tornou-se possível e deu origem, como Kant coloca, “aos primeiros começos da cultura, das artes, do entretenimento como também da industriosidade" ("Daraus mußte Kultur entspringen und der Anfang der Kunst, des Zeitvertreibes sowobl als des Fleißes"). Nesse ponto, Kant adiciona uma referência ao livro do "Gênesis" 24 , o que torna claro que ele não estava pensando somente nas artes no sentido das "belas artes", mas também nas artes aplicadas, nos ofícios e na indústria, na medida em que o "Gênesis" menciona não apenas os harpistas e os flautistas que descendem de Jubal, como também Tubalcaim e seus descendentes, os quais forjaram todo tipo de ferramentas do bronze e do ferro. É exatamente no contexto das artes aplicadas e práticas, da industriosidade, que Kant descreve as origens de "algum tipo de ordem civil e administração pública da justiça [... e portanto] de um tipo de governo". De acordo com Kant, consequentemente, é onde indústria e comércio se enraizaram, nas aldeias e cidades, que as origens da liberdade política podem ser encontradas. Sob essas fundações, Kant explica, "todas as habilidades humanas [“alle menschliche Kunst’] puderam gradualmente desenvolver-se, habilidades das quais a sociabilidade e garantia da segurança pública são as mais benéficas". Kant conclui essa parte de seu raciocínio com a famosa fórmula que expressa sua estima por Rousseau, mas igualmente, de modo tangível, algumas reservas em relação às teses desse autor:

traduzido por L. W. Beck, R. E. Anchor e E. L. Fackenheim, ed. por L. W. Beck, Indianapolis, Bobbs-Merrill, 1963; KPW = Kant's political writings, ed. por H. Reiss, traduzido por H. B. Nisbet, Cambridge, University Press, 1970; 21991.

${ }^{23}$ AA, Vol. VIII, p. 119; RR, p. 79; OH, p. 64. [Para a tradução em português, usamos KANT, I. Começo conjectural da história humana. Tradução de Edmilson Menezes. São Paulo: Editora Unesp, 2010, p. 32 - doravante KANT (2010)]

${ }^{24}$ Cap. IV, linhas 21-22. 
Com essa época, também, começou a desigualdade humana, essa fonte abundante de tantos males, mas igualmente de tudo que é bom. Posteriormente, a desigualdade cresceu. ("Mit dieser Epoche fing auch die Ungleichheit unter den Menschen, diese reiche Quelle so vielen Bösen, aber auch alles Guten, an und nahm fernerhin zu.")

"A desigualdade humana [...] fonte de [...] tudo que é bom", obviamente, Rousseau nunca teria dito algo assim, mas eu darei sequência à conexão com Rousseau um pouco depois. Kant prossegue falando da "guerra contínua" ou, "no mínimo, do perigo contínuo da guerra" entre o povo nômade de pastores e os habitantes e agricultores citadinos; e no entanto, quase paradoxalmente, é nessa situação dramática de guerra ou perigo que, segundo Kant, “os dois lados podem [...] se regozijar na posse inestimável da liberdade”. Na explicação seguinte, e isso é significativo, Kant avança explicitamente a seu próprio tempo: "auch noch jetz̨t" “mesmo agora”, ele escreve, “o perigo da guerra é o único fator que mitiga o despotismo. Pois um Estado não pode ser poderoso a não ser que seja rico, mas sem liberdade, atividades de produção de riqueza não podem florescer"25.

Antes de tentar explicar as várias implicações dessa afirmação, pode ser útil levar em conta o segundo trecho, uma passagem retirada da "Ideia de uma história universal de um ponto de vista cosmopolita”, oitava proposição ${ }^{26}$. Na proposição precedente, a sétima, Kant já havia mostrado que "o problema do estabelecimento de uma constituição civil perfeita é subordinado ao problema de uma relação externa legal com outros Estados" 27 e ele havia deixado claro que tanto a relação entre Estados, quanto a discórdia entre indivíduos em qualquer comunidade particular, era determinada pela insociabilidade: guerras, os perigos da guerra, e assim preparações militares incessantes persistem entre eles. Os conflitos entre os Estados bem como a discórdia entre os indivíduos são nutridos pela mesma ambição. Aqui novamente, no caso das relações internacionais, Kant passa deliberadamente, com um enfático "jetət [...] schon" — "atualmente" 28 — de uma reflexão geral à uma consideração da

\footnotetext{
${ }^{25} \mathrm{OH}$, p. 65; RR, p. 80. [KANT (2010), p. 34].

${ }^{26}$ AA, Vol. VIII, pp. 27 e ss.; RR, pp. 33 e ss.; OH, pp. 21 e ss.; KPW, pp. 50 e ss. [Para a tradução em português, usamos KANT, I. Ideia de uma história universal de um ponto de vista cosmopolita. Trad. Ricardo R. Terra e Rodrigo Naves. São Paulo: Editora WMF Martins Fontes, 2011, pp. 17 e ss. - doravante KANT (2011)]

${ }^{27} \mathrm{AA}$, Vol. VIII, pp. 24; RR, pp. 29 e ss.; OH, p. 18; KPW, p. 47. [KANT (2011), p. 12]

${ }^{28}$ RR, p. 34; OH, p. 22. [KANT (2011), p. 18]
} 
situação concreta em seu próprio tempo. Ele afirma que nenhum Estado "atualmente", "pode negligenciar seu desenvolvimento cultural interno", em outras palavras, seu nível de refinamento e civilização, "sem perder poder e influência entre os outros". Kant conclui que a "liberdade civil" ("bürgerliche Freiheit"), "não pode mais ser facilmente infringida" - ele parece fazer um uso consciente do significado duplo do termo "bürgerlich" pois, no seu entender, os dois tipos de liberdade [freedom] $]^{29}$, econômica e política, estão ligados. Ele também conclui que o Estado, culpado de tal infração, sofreria uma "desvantagem para todas as negociações e indústrias, e especialmente para o comércio, ocasião na qual o poder do Estado em suas relações externas” também declinaria. A liberdade assim assegurada, Kant adiciona, irá se ampliar em graus. É a ambição dos Estados, “os esquemas de expansão egoístas dos governantes", que os leva a infringir cada vez menos as liberdades de seus súditos. "A liberdade [freedom] geral de religião", esse fruto precioso do Enlightenment, e a Aufklärung ela mesma, que Kant menciona explicitamente nesse contexto, não se originam na boa vontade de certos soberanos, mas emergem paradoxalmente dos seus ambiciosos projetos.

A conclusão a ser tirada das duas passagens de Kant, é a de uma relação dupla entre a liberdade e o progresso da indústria e do comércio. Os primeiros rudimentos da liberdade, a proteção em relação à violência arbitrária garantida ao indivíduo, os esforços em direção à constituição civil, uma administração pública da justiça, em direção a, como coloca Kant, "um tipo de governo”, são os resultados do progresso realizado na indústria e no comércio. Esses rudimentos de liberdade são então consolidados e desenvolvidos em graus. A liberdade, que talvez inicialmente aparece limitada a questões econômicas e à segurança do indivíduo, gradualmente se amplia para concernir-se, por exemplo, com o direito de deslocarse e de estabelecer-se livremente, ou com o direito de liberdade religiosa. Esses direitos, essa liberdade — parece justo concluir, mesmo se Kant utiliza o argumento sobretudo em sua forma negativa, quando ele diz que as restrições sobre a liberdade [freedom] pessoal impedem o desenvolvimento econômico — fomenta por sua vez a atividade industrial e comercial ("die Lebhaftigkeit des durchgängigen Betriebes").

\footnotetext{
${ }^{29}$ Estão assinalados os usos do termo em inglês "freedom", as demais traduções de "liberdade" correspondem ao termo em inglês "liberty". [Nota dos tradutores].
} 
Segundo Kant, de fato, os dois movimentos não são sucessivos, mas completam e reforçam um ao outro mutuamente em cada nível. Se se adota uma perspectiva suficientemente ampla, talvez se possa dizer que os resultados dessa interação fornecem à Kant razões para ser confiante com respeito ao desenvolvimento dos países europeus. Com tal perspectiva, Kant afirma na nona proposição de seu artigo, "nós devemos descobrir um processo regular de aprimoramento nas constituições políticas de nosso continente",30.

Logo antes dessas duas passagens, Kant menciona Rousseau explicitamente, mas o interpreta em sua própria maneira não ortodoxa, de tal modo não ortodoxa que Alexis Philonenko, um estudioso francês de Kant dos mais proeminentes, acusa Kant de "sistematicamente deformar a doutrina de Rousseau"31. Em sua sétima proposição, Kant associa Rousseau com o abbé de Saint-Pierre ${ }^{32}$; e em sua "História conjectural", ele o apresenta como um partidário do progresso ${ }^{33}$. De acordo com Philonenko, Kant era consciente do "perigo" que Rousseau representava, pois esse autor "ameaçava todos aqueles que acreditavam no progresso" 34 . Uma outra hipótese, apresentada por Jean-Michel Muglioni em seu estudo recente sobre a filosofia da história de Kant, é que Kant era sincero em sua convicção de que o postulado do progresso já podia ser encontrado em Rousseau — na medida em que, uma vez levados em conta os juízos morais de Rousseau, esse postulado não poderia estar ausente em sua obra. ${ }^{35}$

Seja consciente ou inconscientemente, Kant deformou Rousseau: eu suponho que todos concordam a esse respeito. Mas é somente contra Rousseau, e exclusivamente em relação a ele, que Kant elaborou sua própria concepção de história? Kant tinha lido também Hume e uma análise atenta de seus próprios escritos sobre história revelam ecos claros dessa leitura. Minha tese da dívida de Kant a Hume não é somente uma conjectura na base de similaridades textuais que, por si mesmas, não podem nunca ser conclusivas, mesmo se as similaridades são

\footnotetext{
${ }^{30}$ RR, p. 37; AA, T. VIII, p. 29; KPW, p. 52; OH, p. 24. [KANT (2011), pp. 20-21].

${ }^{31}$ PHILONENKO, A., L'oeuvre de Kant, 2 vol., Paris, Vrin, 1969-1972, Vol. II (31988), p. 43.

${ }^{32}$ RR, p. 17; KPW, p. 47; OH, p. 19. [KANT (2011), p. 13]

${ }^{33} \mathrm{RR}$, pp. 75 e ss.; OH, pp. 60 e ss. [KANT (2010), pp. 25 e ss.]

${ }^{34}$ PHILONENKO, A. (31998) [ver nota 29], p. 43, "menaçait tous ceux qui croyaient au progrès".

${ }^{35}$ Cf. MUGLIONI, J.-M., La philosophie de l'histoire de Kant, Paris, PUF, 1993, pp. 144 e ss.
} 
convincentes. Quando o artigo de Kant sobre a "Ideia de uma história universal" é seguido apenas um pouco mais que o extrato aqui utilizado, encontramos Kant citando Hume numa nota à sua nona proposição, na qual ele aprova a opinião de Hume segundo a qual "a primeira página de Tucídides [...] é o único começo de toda verdadeira história" ${ }^{36}$.

\section{III.}

Em conclusão, gostaria de considerar algumas reservas em relação ao meu argumento. Quando Kant sublinha a relação de refinamento nas artes e o desenvolvimento da indústria e do comércio para o progresso da liberdade, ele o faz num contexto preciso, numa discussão de relações externas conflituosas entre Estados diferentes. $\mathrm{O}$ argumento de Hume no ensaio sobre o luxo, deve ser admitido, é mais geral e contudo, nesse mesmo ensaio, Hume estava bem ciente de suas implicações para as relações internacionais: como pode ser encontrado, por exemplo, na passagem na qual ele contrasta a extensão das campanhas militares de Carlos VIII e de Luís XIV, respectivamente; e na qual ele interpreta as principais diferenças entre eles como a consequência de desenvolvimentos econômicos ${ }^{37}$. Em outros ensaios de Hume, uma análise das conexões existentes entre o refinamento, a liberdade [freedom] do indivíduo, e as relações externas dos Estados está prontamente disponível, por exemplo em seu ensaio "Da balança de poder" e, pouco antes do ensaio sobre os refinamentos nas artes, no ensaio "Do comércio", no qual Hume explica que o "luxo dos indivíduos diminui a força, e põe freio à

\footnotetext{
${ }^{36}$ RR, p. 37; KPW, p. 52; OH, p. 24. Em Hume, encontramos essa afirmação no seu ensaio "Of the populousness of Ancient Nations", HUME, Essays, p. 422.

${ }^{37}$ HUME, Essays, p. 273, “As fronteiras de todos os reinos da Europa são no presente quase as mesmas de duzentos anos atrás: mas que diferença não há no poder e grandeza desses reinos! Isso não pode ser atribuído a outra coisa senão ao incremento da arte da indústria. Quando Carlos VIII da França invadiu a Itália, levou consigo cerca de vinte mil homens, contingente que exauriu de tal modo a nação, que, como nos informa Guicciardini, por alguns anos ela não foi capaz de fazer outro grande esforço como este. Em tempo de guerra, o falecido rei da França [i. e., Luís XIV; N. W.] mantinha mais de quatrocentos mil homens pagos, embora entre a morte de Mazarino [1661] e a sua própria [1715] ele tenha se envolvido numa série de guerras que duraram quase trinta anos". [HUME (2008), p. 213]
} 
ambição do soberano" ${ }^{38}$. Essas últimas frases revelam um ponto ainda mais importante, um ponto que mostra a proximidade das perspectivas de Kant e de Hume. O que a história e a experiência mostram a Hume, é na verdade um progresso em direção a maior liberdade, civil e política. Mas esse progresso é com frequência ocasionado por causas como o luxo dos indivíduos, a ambição dos príncipes e assim por diante. Para Hume, como para Kant, o progresso que pode ser observado na história não é devido à boa vontade dos monarcas esclarecidos. Ele não subscreve à ideia de que o progresso é inevitavelmente necessário. Mesmo quando, a seus olhos, o progresso teve lugar, Hume sublinha as paixões, as superstições, a violência e o elemento do acaso que contribuíram para sua realização.

RECEBIDO: $22 / 11 / 2019$ APROVADO: $21 / 03 / 2020$

RECEIVED: $11 / 22 / 2019$

APPROVED: 03/21/2020

${ }^{38}$ HUME, Essays, p. 257. [HUME (2008), p. 198] 